\title{
Synaptotagmin I Synchronizes Transmitter Release in Mouse Hippocampal Neurons
}

\author{
Tei-ichi Nishiki and George J. Augustine \\ Department of Neurobiology, Duke University Medical Center, Durham, North Carolina 27710
}

\begin{abstract}
We have asked whether loss of the $\mathrm{Ca}^{2+}$ sensor protein synaptotagmin I influences the total amount of neurotransmitter released after a presynaptic action potential. Hippocampal neurons from synaptotagmin I knock-out mice had a greatly reduced fast synchronous component of glutamate release, as reported previously. However, the amount of glutamate released during the slow asynchronous component increased in these knock-out neurons. As a result of these changes in the kinetics of release, there was no significant difference between wild-type and knock-out neurons in the total amount of transmitter released within $400 \mathrm{msec}$ after a presynaptic stimulus. Fluorescence imaging experiments demonstrated that wild-type and knock-out neurons take up and release similar amounts of FM dye after depolarization, indicating normal amounts of synaptic vesicle trafficking in the knock-out neurons. These results indicate that synaptotagmin I knock-out neurons are fully capable of releasing neurotransmitter, with the increased slow component of release serving to compensate for loss of the fast component. Thus, synaptotagmin I synchronizes the rapid release of neurotransmitters after $\mathrm{Ca}^{2+}$ entry into presynaptic terminals and also appears to suppress the slower, asynchronous form of transmitter release.
\end{abstract}

Key words: synaptic transmission; synaptic vesicle; calcium; exocytosis; endocytosis; FM 4-64

\section{Introduction}

Synaptic transmission relies on the synchronous release of neurotransmitters after a presynaptic action potential. Presynaptic activity causes an influx of calcium ions $\left(\mathrm{Ca}^{2+}\right)$, which serve as a second messenger for triggering neurotransmitter release. Understanding the molecular mechanisms of neurotransmitter release requires identification of the presynaptic molecules that serve as $\mathrm{Ca}^{2+}$ sensors. The best candidate for this role is the synaptic vesicle protein synaptotagmin I (Augustine, 2001; Chapman, 2002; Südhof, 2002; Koh and Bellen, 2003). Synaptotagmins are a large family of integral membrane proteins with a cytoplasmic region that contains two copies of a $\mathrm{Ca}^{2+}$-binding motif called the $\mathrm{C}_{2}$ domain (Südhof, 2002). These $\mathrm{C}_{2}$ domains work in coordination with membrane phospholipids to confer $\mathrm{Ca}^{2+}$ binding to synaptotagmin (Brose et al., 1992; Sutton et al., 1995; Fernandez et al., 2001). Although both $\mathrm{C}_{2}$ domains of synaptotagmin are capable of binding $\mathrm{Ca}^{2+}$, binding to the second $\mathrm{C}_{2}$ domain $\left(\mathrm{C}_{2} \mathrm{~B}\right)$ of synaptotagmin I seems to play a more important role (Fernández-Chacón et al., 2002; Mackler et al., 2002; Robinson et al., 2002; Stevens and Sullivan, 2003). $\mathrm{Ca}^{2+}$ binding triggers rapid changes in the biochemical properties of synaptotagmin, most notably causing rapid binding to several molecular components involved in membrane fusion, including SNARE (soluble $\mathrm{N}$-ethylmaleimide-sensitive factor attachment protein

Received April 23, 2004; revised May 26, 2004; accepted May 26, 2004.

This work was supported by National Institutes of Health Grant NS-21624 and National Institute of Mental Health Grant MH-67044. We thank D. Gitler, C. Villalba, and Y. Li for comments on this manuscript.

Correspondence should be addressed to George J. Augustine, Department of Neurobiology, Duke University Medical Center, Box 3209, Durham, NC 27710. E-mail: georgea@neuro.duke.edu. DOI:10.1523/JNEUROSCI.1563-04.2004

Copyright $\odot 2004$ Society for Neuroscience $\quad$ 0270-6474/04/246127-06\$15.00/0 receptor) proteins and membrane lipids (Davis et al., 1999; Bai et al., 2004a,b).

Several lines of evidence support the involvement of synaptotagmin I in $\mathrm{Ca}^{2+}$-dependent neurotransmitter release. The main evidence is that synaptic transmission is greatly attenuated after perturbation of synaptotagmin function. For example, presynaptic injection of synthetic peptides from synaptotagmin (Bommert et al., 1993; Fukuda et al., 2000), microinjection of antisynaptotagmin antibodies (Mikoshiba et al., 1995), and knockout of synaptotagmin genes in flies, nematodes, and mice (DiAntonio et al., 1993; Littleton et al., 1993; Nonet et al., 1993; Geppert et al., 1994) all reduce the amplitude of postsynaptic responses elicited by presynaptic action potentials.

However, there are indications that $\mathrm{Ca}^{2+}$-dependent transmitter release is not completely eliminated after loss of synaptotagmins. Shoji-Kasai et al. (1992) reported that the amount of neurotransmitter release evoked by prolonged depolarization is unchanged in synaptotagmin I-deficient pheochromocytoma 12 (PC12) cells. In mouse hippocampal neurons, knock-out of the synaptotagmin I gene does not eliminate a slow asynchronous component of evoked transmitter release (Geppert et al., 1994), and this component is reported to increase after knock-out of synaptotagmin from Drosophila neurons (Yoshihara and Littleton, 2002). Thus, it is possible that loss of synaptotagmin I does not eliminate transmitter release but instead reduces the peak amplitude of postsynaptic responses simply by desynchronizing release relative to the presynaptic stimulus. To consider this possibility, we have examined transmitter release from hippocampal neurons cultured from synaptotagmin I knock-out mice and have indeed found that the total amount of transmitter release is unchanged after knock-out of synaptotagmin. This indicates that the role of synaptotagmin I in mouse neurons is to synchronize 
neurotransmitter release in response to presynaptic action potentials rather than to control the absolute amount of release.

\section{Materials and Methods}

Cell culture. Heterozygous synaptotagmin I-deficient mice, produced by Geppert et al. (1994), were purchased from The Jackson Laboratory (Bar Harbor, ME). Procedures used to maintain and use these mice were approved by the Duke University Animal Care and Use Committee. Newborn pups (postnatal day 0 ) were genotyped by PCR and then killed to prepare hippocampal neurons, as described by Gitler et al. (2004). Microisland cultures of hippocampal neurons were prepared as described previously (Bekkers and Stevens, 1991; Feng et al., 2002), with the addition of glia feeder cells to support neuronal survival. Neurons were allowed to mature for $9-13 \mathrm{~d}$ before being used for electrophysiological recordings.

Electrophysiology. Whole-cell patch-clamp recordings were made from single neurons on microislands, as described by Feng et al. (2002). Patch pipettes $(2-3 \mathrm{M} \Omega$ ) were filled with intracellular solution containing (in mM): $50 \mathrm{~K}$-glutamate, $71 \mathrm{~K}$-gluconate, $15 \mathrm{NaCl}, 6 \mathrm{MgCl}_{2}, 2$ EGTA, 5 $\mathrm{Na}_{2} \mathrm{ATP}, 5 \mathrm{Na}_{2} \mathrm{GTP}$, and 20 HEPES-KOH, pH 7.3 (285 mOsm). The extracellular solution contained (in $\mathrm{mM}$ ): $150 \mathrm{NaCl}, 3 \mathrm{KCl}, 2 \mathrm{CaCl}_{2}, 2$ $\mathrm{MgCl}_{2}, 20$ glucose, and 10 HEPES-NaOH, pH 7.3 (300 mOsm). Neurons were voltage clamped at $-70 \mathrm{mV}$ with a PC-501 amplifier (Warner Instruments, Hamden, CT) and stimulated by depolarizing to $+20 \mathrm{mV}$ for $0.8 \mathrm{msec}$ every $5 \mathrm{sec}$. Only cells with series resistances of $<15 \mathrm{M} \Omega$ were analyzed, with $60-70 \%$ of this resistance compensated.

FM dye imaging experiments. Neurons were plated onto poly-D-lysinetreated coverslips at a density of $4 \times 10^{4} \mathrm{cells} / \mathrm{cm}^{2}$ and examined with an inverted fluorescence microscope (IX 70; Olympus Optical, Melville, NY) equipped with a $20 \times$ objective (numerical aperture, 0.75 ), a $540 \pm$ $10 \mathrm{~nm}$ bandpass excitation filter, and a $590 \mathrm{~nm}$ long-pass emission filter. Cells were labeled with FM 4-64 (5 $\mu$; Molecular Probes, Eugene, OR) by depolarization with an extracellular solution containing $90 \mathrm{mM} \mathrm{KCl}$ and $63 \mathrm{~mm} \mathrm{NaCl}$ (high $\mathrm{K}^{+}$solution) and then washed for $15 \mathrm{~min}$. Dye was unloaded by treating with the high $\mathrm{K}^{+}$solution $(1.5 \mathrm{~min})$ in the absence of extracellular dye. Images were acquired with a CoolSNAP $\mathrm{fx}_{\mathrm{fx}}$ cooled CCD camera (Roper Scientific, Tucson, AZ) and ESee software (Inovision, Raleigh, NC) and analyzed using ISee software (Inovision). Eight synaptic boutons were selected for analysis of each experiment, with changes in dye fluorescence determined by subtracting the fluorescence intensities measured after the high $\mathrm{K}^{+}$stimulus from those measured before the stimulus.

\section{Results}

\section{Altered kinetics of neurotransmitter release from synaptotagmin-deficient neurons}

To measure the influence of synaptotagmin on neurotransmitter release, we prepared microisland cultures of hippocampal neurons from newborn synaptotagmin I knock-out mice and sibling wild-type controls. Whole-cell patch-clamp recordings were used to measure EPSCs resulting from action potentials evoked by brief depolarizations. EPSCs were large in wild-type neurons and greatly reduced in amplitude in the knock-out neurons (Fig. $1 A)$. Although the peak amplitude of EPSCs was quite variable from one autapse preparation to the next, the mean peak amplitude of EPSCs in knock-out neurons was $~ 15 \%$ of that found in wild-type neurons (Fig. $1 B$ ). This difference was statistically significant ( $p<0.005$; Mann-Whitney test) and is similar to previous results reported for synaptotagmin I null mice (Geppert et al., 1994) and flies (DiAntonio et al., 1993; Littleton et al., 1993).

The kinetics of neurotransmitter release was also altered after loss of synaptotagmin I. The EPSC traces illustrate that the time required for EPSCs to reach their peak was longer for knock-out neurons than for wild-type cells (Fig. $1 A$ ). This change was quantified by measuring EPSC peak latency: whereas $\sim 90 \%$ of the
A
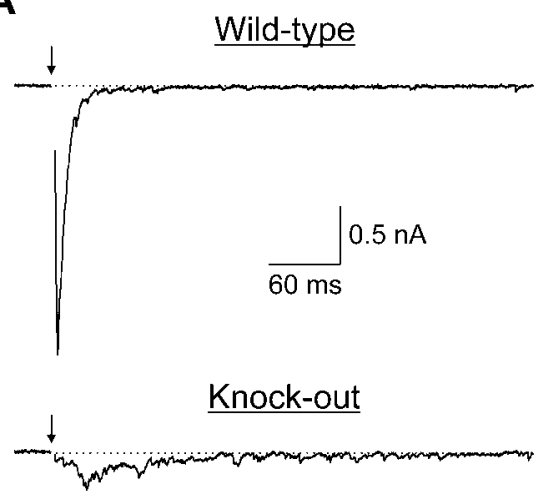

B

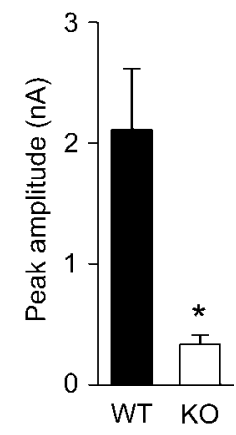

C
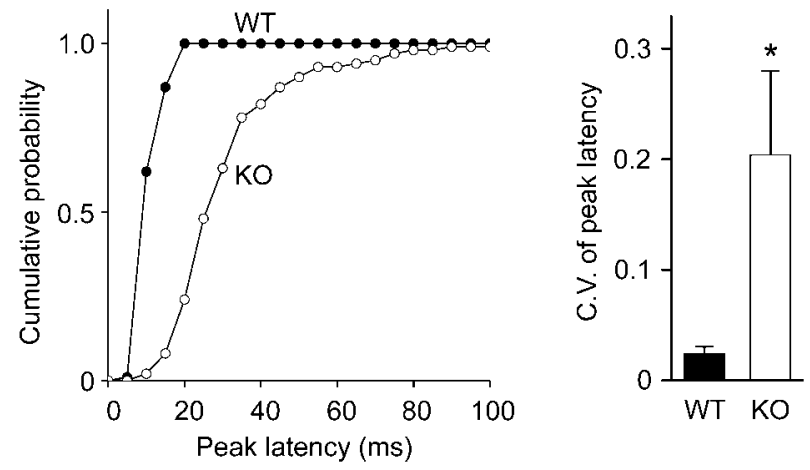

Figure 1. Alterations in evoked transmitter release in synaptotagmin I knock-out neurons. $A$, EPSCs recorded from neurons from wild-type and synaptotagmin I knock-out mice. Cells were held at $-70 \mathrm{mV}$, and action potentials were induced by brief depolarizations (arrows); stimulus artifacts are blanked. $B$, Peak amplitudes of EPSCs in wild-type (WT; $n=11)$ and knock-out (KO; $n=11)$ neurons. Values in this and subsequent figures indicate mean \pm SEM, and asterisks indicate statistically significant differences. C, D, Cumulative probabilities and coefficients of variation of EPSC peak latency from wild-type and knock-out neurons.

EPSCs recorded from wild-type neurons peaked within $15 \mathrm{msec}$ after the stimulus, $<10 \%$ of the EPSCs peaked during this time period in the knock-out neurons (Fig. 1C). The latency for EPSCs to reach their peak in individual neurons was also more variable for knock-out cells, with a coefficient of variation (SD divided by mean peak latency) 10 times larger than that of wild-type neurons $(p<0.005)$ (Fig. 1D)

As described previously (Geppert et al., 1994; Yoshihara and Littleton, 2002; Shin et al., 2003), the duration of EPSCs was also prolonged in knock-out neurons (Fig. $1 A$ ). These changes were described by integrating EPSCs over time to define the kinetics of postsynaptic charge transfer. In both wild-type and knock-out neurons, the kinetics of EPSC charge could be described by double exponential functions (Fig. 2A). In knock-out neurons, the time constant of the first component of release $(46.3 \pm 5.0 \mathrm{msec})$ was 4.5 -fold slower than that for the wild-type neurons $(10.4 \pm$ $0.8 \mathrm{msec})$. This difference is statistically significant $\left(p<10^{-5}\right)$. The time constant of the slow, asynchronous component of release was similar for both knock-out $(298 \pm 32 \mathrm{msec})$ and wildtype (241 $\pm 32 \mathrm{msec})$ neurons and was not significantly different $(p>0.1)$. Although the amplitude of the fast component of release was much greater in wild-type neurons, the amplitude of the slow component was greater in the knock-out neurons (Fig. 2B). We also used a deconvolution analysis (Van der Kloot, 1988) 
A

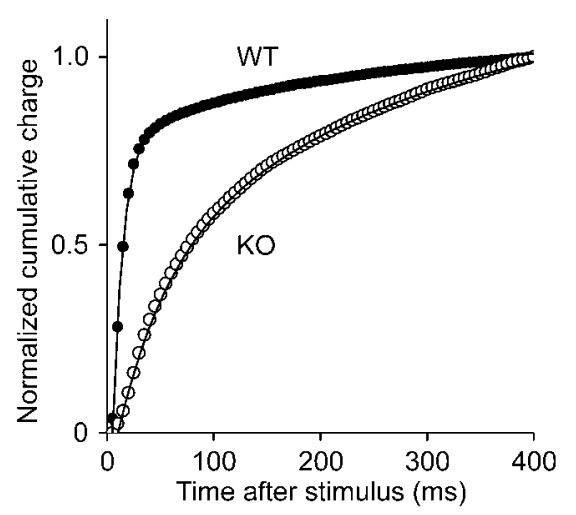

B

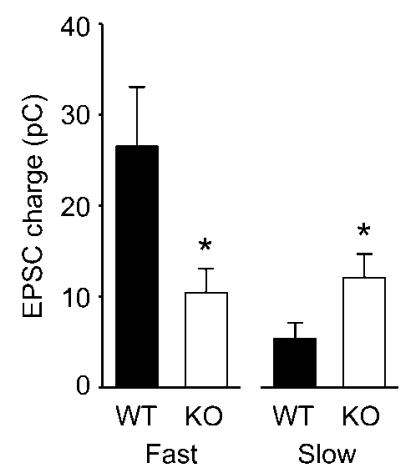

C

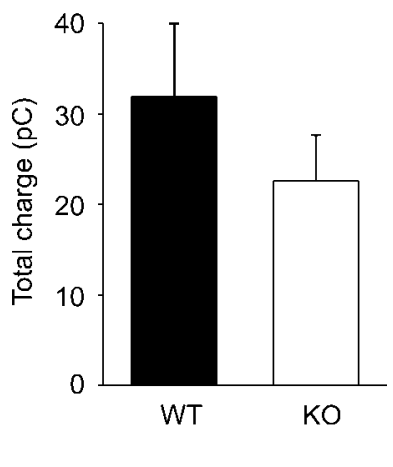

Figure 2. Altered release kinetics in synaptotagmin I knock-out neurons. $A$, Cumulative EPSC charge was calculated for wild-type (WT; $n=11$ ) and knock-out (K0; $n=11)$ neurons for 400 msec after the stimulus. Solid lines are double-exponential functions fit to the data. $B$, Amplitudes of fast and slow components of release from wild-type and knock-out neurons, estimated from the magnitudes of each exponential component shown in $A$. Asterisks indicate statistically significant differences. C, Total amount of EPSC charge produced by wild-type and knock-out neurons for 400 msec after the stimulus.

to independently estimate rates of transmitter release. This analysis also indicated that release consists of two kinetically distinct components of release. The relative amplitudes of these two components were identical to those determined from EPSC integrals, and their time constants were $16-33 \%$ faster than the values determined from EPSC integrals (data not shown). These data indicate that loss of synaptotagmin I slows and attenuates the first component of release, consistent with previous reports (Geppert et al., 1994; Shin et al., 2003). Loss of synaptotagmin I also yields an increase in the amount of slow asynchronous release, as reported in Drosophila (Yoshihara and Littleton, 2002).

Given these changes in the kinetics of release in synaptotagmin-deficient neurons, the peak amplitude of EPSCs (Fig. $1 B$ ) will not accurately represent the total amount of transmitter release. We therefore compared the cumulative amount of charge transfer associated with EPSCs for $400 \mathrm{msec}$ after the stimulus. Remarkably, there was no significant difference $(p>0.15)$ in EPSC charge between the two types of neurons (Fig. 2C). This conclusion was unchanged when EPSC charge was determined for $1 \mathrm{sec}$ after the stimulus (data not shown). Thus, although the peak amplitude and the kinetics of EPSCs depend on synaptotagmin I, the total amount of transmitter released is not significantly different despite the absence of synaptotagmin I. This appears to be attributable to a compensatory increase in the amount of slow asynchronous release after the loss of synaptotagmin I.
A

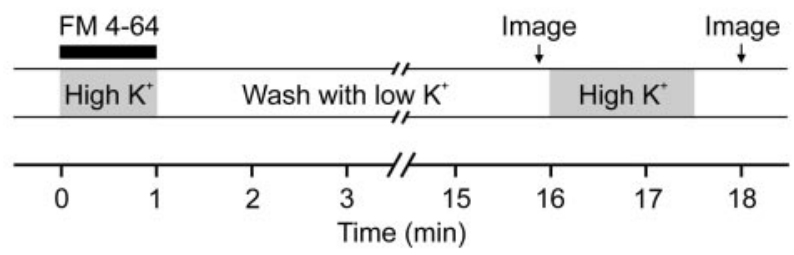
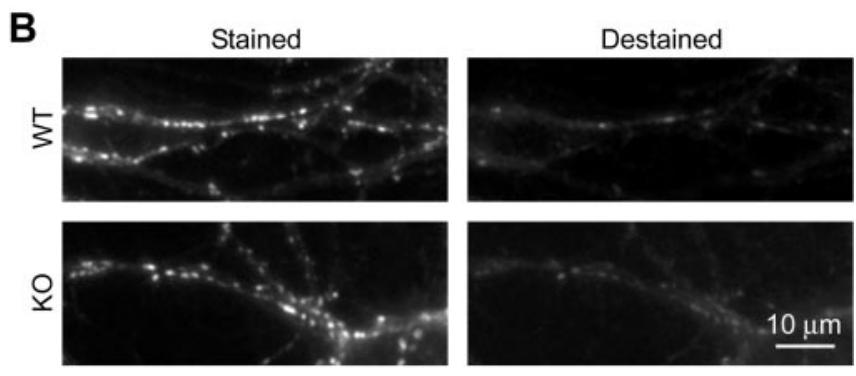

C

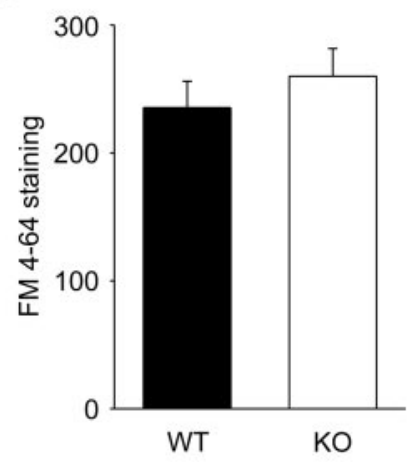

D
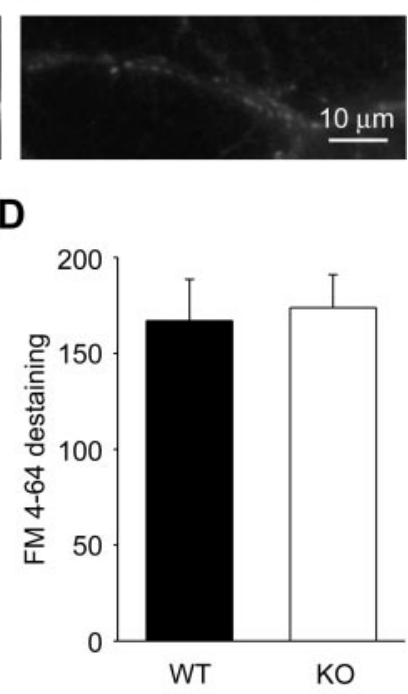

Figure 3. Intact exocytosis and endocytosis in synaptotagmin I knock-out neurons. A, Neurons were stimulated by depolarization with a high $\mathrm{K}^{+}$solution in the presence or absence of FM 4-64 dye, and fluorescence images were acquired at the times indicated. $B$, Representative images of synaptic arbors after staining with FM 4-64 (left) and subsequent destaining with high $\mathrm{K}^{+}$solution in the absence of dye (right) in wild-type (WT; top) and knock-out (KO; bottom) neurons. C, D, Quantification of FM 4-64 staining ( $C$ and destaining $(D)$. Data were obtained from three independent experiments.

\section{Unaltered FM dye uptake and release in synaptotagmin-deficient neurons}

To provide an alternative measure of the amount of transmitter released from synaptotagmin knock-out neurons, we used FM dye imaging to measure synaptic vesicle exocytosis (Betz et al., 1996; Ryan, 2001). Wild-type and knock-out neurons were stimulated, in the presence of FM 4-64, with an extracellular solution containing a high $(90 \mathrm{~mm})$ concentration of $\mathrm{K}^{+}$. After extensive washing with dye-free solution containing a normal concentration of $\mathrm{K}^{+}(3 \mathrm{mM})$, presynaptic terminals were imaged to determine the extent of dye uptake (Fig. 3A). A similar amount of dye staining was observed in synapses of both wild-type and knockout neurons (Fig. 3B, left). Measurements of the intensity of dye fluorescence in synaptic regions showed no significant difference between wild-type and knock-out neurons $(p>0.2)$ (Fig. 3C), indicating that synapses still retain functional exocytosis and endocytosis in the absence of synaptotagmin I. To selectively examine exocytosis, stained terminals were destained by exposure to an extracellular solution containing high $\mathrm{K}^{+}$but no FM 4-64 (Fig. 3B, right). Quantitative analysis showed that there was no significant difference $(p>0.8)$ between the amount of dye 
destaining measured in wild-type and knock-out neurons (Fig. $3 D$ ). Thus, loss of synaptotagmin I has no effect on the amount of stimulus-evoked exocytosis reported by the FM dye.

\section{Discussion}

We have examined neurotransmitter release from mouse neurons containing no synaptotagmin I. Although several studies have considered either the peak magnitude or the time course of transmitter release in synaptotagmin-deficient neurons, ours is the first to examine the total amount of transmitter released. Using two different methods, electrical measurements of EPSCs and FM dye imaging of vesicle exocytosis, we found that loss of synaptotagmin I does not significantly alter the total amount of transmitter release. Thus, we conclude that synaptotagmin I is not absolutely required for $\mathrm{Ca}^{2+}$-dependent synaptic vesicle exocytosis.

Although these results are somewhat surprising, given previous indications that synaptotagmin I serves as a $\mathrm{Ca}^{2+}$ sensor for neurotransmitter release, our findings are consistent with previous results. For example, Shin et al. (2003) reported that within the first $100 \mathrm{msec}$ after a stimulus, 233 quanta of transmitter are released from wild-type neurons and 150 quanta are released from mouse hippocampal neurons deficient in synaptotagmin I. However, these values are reported to correspond to $\sim 90$ and $50 \%$ of the total amount of transmitter released from wild-type and knock-out neurons, respectively, within $1 \mathrm{sec}$ (Shin et al., 2003). Thus, the total amount of transmitter released in $1 \mathrm{sec}$ would then be very similar in the two genotypes; 256 quanta would be released from wild-type neurons, and 300 quanta would be released from synaptotagmin knock-out neurons. Our results are also consistent with previous findings that the amount of catecholamine release evoked by prolonged depolarization is unchanged in synaptotagmin I-deficient PC12 cells (Shoji-Kasai et al., 1992).

We found that the amplitude of the fast component of transmitter release was much smaller (and its time constant was fivefold slower) than in wild-type neurons, consistent with previous results in mouse neurons (Geppert et al., 1994; Shin et al., 2003). In contrast, the amplitude of the slow asynchronous component of release was increased, as described in fly neurons (Yoshihara and Littleton, 2002). Together, these opposing changes in the two kinetic components compensated for each other, yielding no net change in the total amount of transmitter release. Because disruption of the mouse synaptotagmin I gene does not affect the size of the readily releasable pool of synaptic vesicles (Geppert et al., 1994, 1997; Shin et al., 2003), it appears that the loss of synaptotagmin reduces the synchronous component of release by decreasing the probability that readily releasable vesicles are able to fuse synchronously after a presynaptic action potential and simultaneously increases the probability that such vesicles will fuse asynchronously. Thus, synaptotagmin I synchronizes the rapid release of transmitter from neurons rather than controlling the total amount of release. Given the increase in asynchronous release in knock-out neurons, it is also likely that synaptotagmin I serves to suppress asynchronous release. We also propose that the increase in slow asynchronous release and concurrent decrease in fast synchronous release that is produced by synprint peptides (Mochida et al., 1996) may be attributable to these peptides binding to, and interfering with, the $\mathrm{C}_{2} \mathrm{~B}$ domain of synaptotagmin I (Sheng et al., 1997).

The conclusion that synaptotagmin I synchronizes rapid release rather than controlling the total amount of release initially seems at odds with the results of numerous microinjection exper-

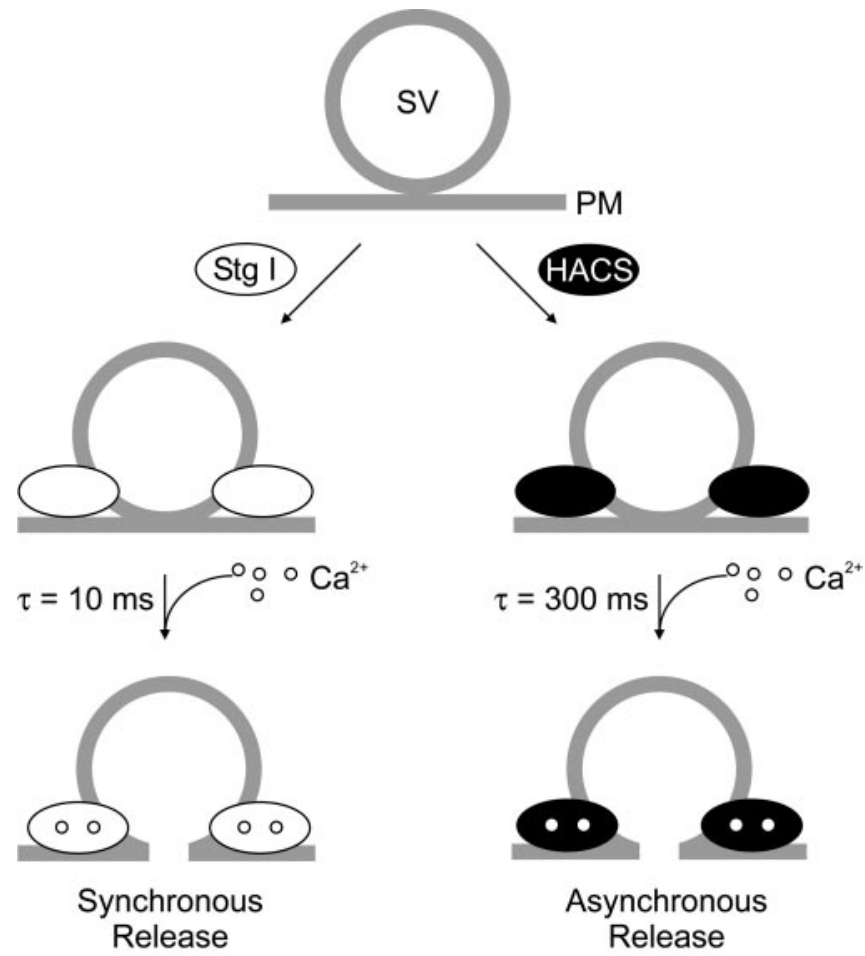

Figure 4. Model for synchronous and asynchronous components of neurotransmitter release. Synaptic vesicles (SV) docked at the presynaptic plasma membrane (PM) enter the readily releasable pool by associating with synaptotagmin I (Stg I) and/or a high-affinity calcium sensor (HACS). Binding of $\mathrm{Ca}^{2+}$ to these two sensors triggers vesicle exocytosis with time constants $(\tau)$ of $\sim 10$ and $300 \mathrm{msec}$, respectively.

iments. These experiments show that synaptotagmin $\mathrm{C}_{2}$-domain fragments (Elferink et al., 1993), $\mathrm{C}_{2}$-domain peptides (Bommert et al., 1993), and anti-synaptotagmin antibodies (Mikoshiba et al., 1995; Ohara-Imaizumi et al., 1997) each inhibit the total amount of vesicle fusion. In addition, at least for the case of the $\mathrm{C}_{2}$-domain peptides, this decrease in release is not associated with any change in release kinetics (Schweizer et al., 1998). Asynchronous release is thought to be triggered by another high-affinity $\mathrm{Ca}^{2+}$ sensor (Goda and Stevens, 1994), perhaps another isoform within the synaptotagmin family (Marquèze et al., 2000; Südhof, 2002). Thus, it is possible that these reagents inhibit synaptotagmin isoforms in addition to synaptotagmin I, thereby affecting both synchronous and asynchronous release mechanisms and reducing the total amount of release.

Our proposal that synaptotagmin I synchronizes neurotransmitter release is in full agreement with previous hypotheses that synaptotagmin I serves as the $\mathrm{Ca}^{2+}$ sensor for synchronous transmitter release (Augustine, 2001; Chapman, 2002; Südhof, 2002; Koh and Bellen, 2003). However, molecular models for the presynaptic function of synaptotagmin I also need to account for the increase in asynchronous release observed in the absence of this protein. These observations can be explained by a model in which synaptotagmin I allows synaptic vesicles within the readily releasable pool to undergo synchronous fusion while another, highaffinity $\mathrm{Ca}^{2+}$ sensor, possibly another synaptotagmin isoform, plays a similar role in directing these vesicles to fuse via an asynchronous mechanism (Fig. 4). This model is very similar to one proposed for the fast and slow components of secretion in adrenal chromaffin cells (Sørensen et al., 2003). After a presynaptic action potential, entering $\mathrm{Ca}^{2+}$ will bind to synaptotagmin I and/or to the high-affinity $\mathrm{Ca}^{2+}$ sensor, with the result that fu- 
sion will occur with both fast and slow kinetics. Because both fusion pathways draw from a common pool of vesicles and a vesicle can fuse only once during a given $\mathrm{Ca}^{2+}$ signaling event, these two mechanisms will compete with each other. The faster pathway would dominate in the wild-type neurons, but knockout of synaptotagmin I would yield the observed increase in the amount of release via the slow asynchronous pathway. This simple model cannot explain why the first component of transmitter release is slowed in knock-out neurons; additional studies will be needed to determine whether this is caused by slowing of the synchronous release mechanism or by speeding up of a component of asynchronous release.

Synaptotagmin I binds to the endocytotic protein AP-2 (Zhang et al., 1994), and this interaction is thought to play an important role in endocytosis of synaptic vesicles in Caenorhabditis elegans, squid, and Drosophila (Fukuda et al., 1995; Jorgensen et al., 1995; Poskanzer et al., 2003). Therefore, we were surprised to observe that synaptotagmin I-deficient mouse neurons are able to take up FM dye just as well as wild-type neurons (Fig. 3B,C). We suspect that this is attributable to compensation by other synaptotagmin isoforms, such as synaptotagmin III, VI, or VIII, that are also capable of binding to AP-2 (Ullrich et al., 1994; Li et al., 1995; Marquèze et al., 2000). Thus, although synaptotagmin I has a unique function in synchronizing neurotransmitter release from mouse neurons, its role in endocytosis is apparently shared with other synaptotagmin isoforms.

\section{References}

Augustine GJ (2001) How does calcium trigger neurotransmitter release? Curr Opin Neurobiol 11:320-326.

Bai J, Tucker WC, Chapman ER (2004a) PIP 2 increases the speed of response of synaptotagmin and steers its membrane-penetration activity toward the plasma membrane. Nat Struct Mol Biol 11:36-44.

Bai J, Wang CT, Richards DA, Jackson MB, Chapman ER (2004b) Fusion pore dynamics are regulated by synaptotagmin $\cdot t$-SNARE interactions. Neuron 41:929-942.

Bekkers JM, Stevens CF (1991) Excitatory and inhibitory autaptic currents in isolated hippocampal neurons maintained in cell culture. Proc Natl Acad Sci USA 88:7834-7838.

Betz WJ, Mao F, Smith CB (1996) Imaging exocytosis and endocytosis. Curr Opin Neurobiol 6:365-371.

Bommert K, Charlton MP, DeBello WM, Chin GJ, Betz H, Augustine GJ (1993) Inhibition of neurotransmitter release by C2-domain peptides implicates synaptotagmin in exocytosis. Nature 363:163-165.

Brose N, Petrenko AG, SüdhofTC, Jahn R (1992) Synaptotagmin: a calcium sensor on the synaptic vesicle surface. Science 256:1021-1025.

Chapman ER (2002) Synaptotagmin: a $\mathrm{Ca}^{2+}$ sensor that triggers exocytosis? Nat Rev Mol Cell Biol 3:498-508.

Davis AF, Bai J, Fasshauer D, Wolowick MJ, Lewis JL, Chapman ER (1999) Kinetics of synaptotagmin responses to $\mathrm{Ca}^{2+}$ and assembly with the core SNARE complex onto membranes. Neuron 24:363-376.

DiAntonio A, Parfitt KD, Schwarz TL (1993) Synaptic transmission persists in synaptotagmin mutants of Drosophila. Cell 73:1281-1290.

Elferink LA, Peterson MR, Scheller RH (1993) A role for synaptotagmin (p65) in regulated exocytosis. Cell 72:153-159.

Feng J, Chi P, Blanpied TA, Xu Y, Magarinos AM, Ferreira A, Takahashi RH, Kao HT, McEwen BS, Ryan TA, Augustine GJ, Greengard P (2002) Regulation of neurotransmitter release by synapsin III. J Neurosci 22:4372-4380.

Fernandez I, Araç D, Ubach J, Gerber SH, Shin O, Gao Y, Anderson RG, Südhof TC, Rizo J (2001) Three-dimensional structure of the synaptotagmin $1 \mathrm{C}_{2} \mathrm{~B}$-domain: synaptotagmin 1 as a phospholipid binding machine. Neuron 32:1057-1069.

Fernández-Chacón R, Shin OH, Königstorfer A, Matos MF, Meyer AC, Gar- cia J, Gerber SH, Rizo J, Südhof TC, Rosenmund C (2002) Structure/ function analysis of $\mathrm{Ca}^{2+}$ binding to the $\mathrm{C}_{2} \mathrm{~A}$ domain of synaptotagmin 1 . J Neurosci 22:8438-8446.

Fukuda M, Moreira JE, Lewis FM, Sugimori M, Niinobe M, Mikoshiba K, Llinás R (1995) Role of the C2B domain of synaptotagmin in vesicular release and recycling as determined by specific antibody injection into the squid giant synapse preterminal. Proc Natl Acad Sci USA 92:10708-10712.

Fukuda M, Moreira JE, Liu V, Sugimori M, Mikoshiba K, Llinás RR (2000) Role of the conserved WHXL motif in the C terminus of synaptotagmin in synaptic vesicle docking. Proc Natl Acad Sci USA 97:14715-14719.

Geppert M, Goda Y, Hammer RE, Li C, Rosahl TW, Stevens CF, Südhof TC (1994) Synaptotagmin I: a major $\mathrm{Ca}^{2+}$ sensor for transmitter release at a central synapse. Cell 79:717-727.

Geppert M, Goda Y, Stevens CF, Südhof TC (1997) The small GTP-binding protein Rab3A regulates a late step in synaptic vesicle fusion. Nature 387:810-814.

Gitler D, Xu Y, Kao HT, Lin D, Lim S, Feng J, Greengard P, Augustine GJ (2004) Molecular determinants of synapsin targeting to presynaptic terminals. J Neurosci 24:3711-3720.

Goda Y, Stevens CF (1994) Two components of transmitter release at a central synapse. Proc Natl Acad Sci USA 91:12942-12946.

Jorgensen EM, Hartwieg E, Schuske K, Nonet ML, Jin Y, Horvitz HR (1995) Defective recycling of synaptic vesicles in synaptotagmin mutants of Caenorhabditis elegans. Nature 378:196-199.

Koh TW, Bellen HJ (2003) Synaptotagmin I, a Ca ${ }^{2+}$ sensor for neurotransmitter release. Trends Neurosci 26:413-422.

Li C, Ullrich B, Zhang JZ, Anderson RG, Brose N, Südhof TC (1995) $\mathrm{Ca}^{2+}$. dependent and -independent activities of neural and non-neural synaptotagmins. Nature 375:594-599.

Littleton JT, Stern M, Schulze K, Perin M, Bellen HJ (1993) Mutational analysis of Drosophila synaptotagmin demonstrates its essential role in $\mathrm{Ca}^{2+}$-activated neurotransmitter release. Cell 74:1125-1134.

Mackler JM, Drummond JA, Loewen CA, Robinson IM, Reist NE (2002) The $\mathrm{C}_{2} \mathrm{~B} \mathrm{Ca}{ }^{2+}$-binding motif of synaptotagmin is required for synaptic transmission in vivo. Nature 418:340-344.

Marquèze B, Berton F, Seagar M (2000) Synaptotagmins in membrane traffic: which vesicles do the tagmins tag? Biochimie 82:409-420.

Mikoshiba K, Fukuda M, Moreira JE, Lewis FM, Sugimori M, Niinobe M, Llinás R (1995) Role of the C2A domain of synaptotagmin in transmitter release as determined by specific antibody injection into the squid giant synapse preterminal. Proc Natl Acad Sci USA 92:10703-10707.

Mochida S, Sheng ZH, Baker C, Kobayashi H, Catterall WA (1996) Inhibition of neurotransmission by peptides containing the synaptic protein interaction site of N-type $\mathrm{Ca}^{2+}$ channels. Neuron 17:781-788.

Nonet ML, Grundahl K, Meyer BJ, Rand JB (1993) Synaptic function is impaired but not eliminated in C. elegans mutants lacking synaptotagmin. Cell 73:1291-1305.

Ohara-Imaizumi M, Fukuda M, Niinobe M, Misonou H, Ikeda K, Murakami T, Kawasaki M, Mikoshiba K, Kumakura K (1997) Distinct roles of C2A and $\mathrm{C} 2 \mathrm{~B}$ domains of synaptotagmin in the regulation of exocytosis in adrenal chromaffin cells. Proc Natl Acad Sci USA 94:287-291.

Poskanzer KE, Marek KW, Sweeney ST, Davis GW (2003) Synaptotagmin I is necessary for compensatory synaptic vesicle endocytosis in vivo. Nature 426:559-563.

Robinson IM, Ranjan R, Schwarz TL (2002) Synaptotagmins I and IV promote transmitter release independently of $\mathrm{Ca}^{2+}$ binding in the $\mathrm{C}_{2} \mathrm{~A}$ domain. Nature 418:336-340.

Ryan TA (2001) Presynaptic imaging techniques. Curr Opin Neurobiol 11:544-549.

Schweizer FE, Dresbach T, DeBello WM, O'Connor V, Augustine GJ, Betz H (1998) Regulation of neurotransmitter release kinetics by NSF. Science 279:1203-1206.

Sheng ZH, Yokoyama CT, Catterall WA (1997) Interaction of the synprint site of $\mathrm{N}$-type $\mathrm{Ca}^{2+}$ channels with the C2B domain of synaptotagmin I. Proc Natl Acad Sci USA 94:5405-5410.

Shin OH, Rhee JS, Tang J, Sugita S, Rosenmund C, Südhof TC (2003) $\mathrm{Sr}^{2+}$ binding to the $\mathrm{Ca}^{2+}$ binding site of the synaptotagmin $1 \mathrm{C}_{2} \mathrm{~B}$ domain triggers fast exocytosis without stimulating SNARE interactions. Neuron 37:99-108. 
Shoji-Kasai Y, Yoshida A, Sato K, Hoshino T, Ogura A, Kondo S, Fujimoto Y, Kuwahara R, Kato R, Takahashi M (1992) Neurotransmitter release from synaptotagmin-deficient clonal variants of PC12 cells. Science 256:1821-1823.

Sørensen JB, Fernández-Chacón R, Südhof TC, Neher E (2003) Examining synaptotagmin 1 function in dense core vesicle exocytosis under direct control of $\mathrm{Ca}^{2+}$. J Gen Physiol 122:265-276.

Stevens CF, Sullivan JM (2003) The synaptotagmin C2A domain is part of the calcium sensor controlling fast synaptic transmission. Neuron 39:299-308.

Südhof TC (2002) Synaptotagmins: why so many? J Biol Chem 277:7629-7632.

Sutton RB, Davletov BA, Berghuis AM, Südhof TC, Sprang SR (1995) Struc- ture of the first $\mathrm{C}_{2}$ domain of synaptotagmin I: a novel $\mathrm{Ca}^{2+} /$ phospholipid-binding fold. Cell 80:929-938.

Ullrich B, Li C, Zhang JZ, McMahon H, Anderson RG, Geppert M, Südhof TC (1994) Functional properties of multiple synaptotagmins in brain. Neuron 13:1281-1291.

Van der Kloot W (1988) Estimating the timing of quantal releases during end-plate currents at the frog neuromuscular junction. J Physiol (Lond) 402:595-603.

Yoshihara M, Littleton JT (2002) Synaptotagmin I functions as a calcium sensor to synchronize neurotransmitter release. Neuron 36:897-908.

Zhang JZ, Davletov BA, Südhof TC, Anderson RG (1994) Synaptotagmin I is a high affinity receptor for clathrin AP-2: implications for membrane recycling. Cell 78:751-760. 